\title{
HELPING STUDENTS ENGAGE WITH WRITTEN FEEDBACK
}

\author{
Heather I. Brody, Grand Canyon University \\ Jennifer M. Santos, Grand Canyon University
}

\section{ABSTRACT}

Instructors consistently complain about students not reading or using feedback. To address this issue, the authors designed an in-class feedback exercise. The authors found that when students recognize the importance of feedback on writing assignments, they look forward to getting, reading, and using such feedback, and instructor efficacy increases.

Every instructor responsible for grading papers knows the time commitment required for providing written feedback. Martin (2015) insisted the substantial amount of time faculty devote to providing written feedback should be grounded in the belief that the feedback will lead to improvements in students' writing. However, most instructors have encountered the reality that many students either do not read feedback or do not improve as a result of feedback (Redd \& Kennette, 2017). Regarding sentence-level concerns, typically referred to under the umbrella of grammar, instructors also worry students will implement instructors' suggestions without comprehending the rationale for suggestions as required for learning (Diab, 2015).

Solving this problem required a pedagogical approach to achieve two goals: getting students to spend time analyzing their feedback and getting students to use their feedback to improve on future assignments. To this end, the authors designed an in-class feedback exercise consisting of three components: 1) class discussion of the role of feedback, 2) individual notes and analysis of feedback on one assignment, and 3) individual reflections about how to apply feedback to future assignments.

\section{FEEDBACK ACTIVITY: AN OVERVIEW}

An initial feedback exercise begins by asking students to privately catalogue how often they read feedback and then brainstorm why professors provide feedback on writing assignments. As students share the possible reasons that professors provide feedback, instructors make a list of their responses and lead a short discussion about what professors and students need to do to make feedback useful. Once shared responsibility has been established, those using standardized feedback comments may find it helpful to share one or two of the most common critical comments with students and have students answer the following questions about the sample comment:

1. Why do you think writers made this mistake?

2. How could writers who received this feedback use this advice to improve?

3. What might happen if writers who receive this feedback don't use this advice to improve?

4. Without the pressure of the personal (students are not examining their own feedback yet), the students tend to see the potential benefit of knowing about an error and the potential harm of proceeding in ignorance.

Capitalizing on this openness to growth requires dedicating class time to individual feedback analysis. Students are instructed to examine their feedback on the prior writing assignment by making a chart: on the left side of the chart, students list abbreviated forms of the positive comments; on the right side of the chart, they are asked to do the same for critical comments. The next step is crucial: for both the positive and critical comments, students should write reasons for why they received these comments. Depending on student comfort levels and class time constraints, offering the option to 
share their lists and rationales with a partner can add depth to analysis as well as catharsis.

The final step of this exercise invites students to reflect on how prior feedback can help with future assignments. A sample prompt might look like this: "Write a reflective paragraph about how you will use your feedback to help you write more successful papers in the future. What will you try to repeat? What will you do differently? Be specific." Instructors may also wish to include goal setting in the prompt to offer students the opportunity to plan their application of the lessons learned from the feedback.

\section{REFLECTING ON THE FEEDBACK ACTIVITY: RESULTS AND IMPLICATIONS}

Implementing the feedback exercise resulted in benefits for the students and the instructors. Perhaps most importantly, all students present in class not only read, but studied their feedback to complete the multi-step exercise and earn participation credit. While the incentive to analyze the feedback may have been the opportunity to earn points, the learning that happened was obvious. Students with different learning styles all began to understand how feedback is relevant for improvement: spatial intelligence was engaged by the chart, opportunity for pair discussions targeted auditory learners, and collating comments in "positive" and "critical" categories provided scientifically-minded students a "data-centric" view of their performance. Indeed, one adult engineering student opined that the exercise was the "most valuable" learning tool for writing. Further, through the sharing of feedback and goals, students developed an enhanced camaraderie when they realized they all had strengths and weaknesses. Students felt less alone when they found peers who had similar struggles, and they found assets to help them progress in peers with different strengths and weaknesses. This even led students to seek help from each other on future assignments, self-selecting into writing communities, since they knew which students in their groups possessed particular strengths.

Additionally, implementing the feedback exercise allowed the authors to feel that providing feedback was genuinely useful. Instead of spending significant amounts of time writing feedback and bemoaning the likelihood that students would not read it (which, overtime, can decrease instructor motivation), the authors knew students would read and process the feedback to complete the in-class exercise. Writing the feedback, even developing standardized comments, began to feel like a meaningful component of their instructional practices with expected results. The authors were pleasantly surprised by the energy this brought to their assessment practices, perhaps even increasing their efficacy as teachers. Indeed, students' appreciation for feedback was evident in enhanced scores in the feedback section of the authors' End of Course Surveys as well as in comments made by students regarding feedback.

During the exercise, students were extremely engaged, and many expressed that the exercise was fun. Students valued the opportunity to ask questions about feedback they did not understand as well as the time to develop a plan for future improvement. Perhaps most importantly, though, students seemed to learn that feedback is valuable. The authors reminded students that they can continue to do the feedback exercise in other classes on their own any time they receive feedback. The authors found that when students recognize the importance of feedback on writing assignments, they look forward to getting, reading, and using such feedback because they know they will continue learning and becoming better writers. While implementing a feedback activity does require dedicating class time, the payoff is absolutely worth it for those instructors who seek to help students improve their writing. 


\section{References}

Diab, N. M. (2015). Effectiveness of written corrective feedback: Does type of error and type of correction matter? Assessing Writing, 24, 16-34. http://dx.doi.org/10.1016/j.asw.2015.02.001

Martin, R. (2015). Rhetoric of teacher comments on student writing. Young Scholars in Writing, 8, 16-29. Retrieved from https://arc.lib.montana.edu/ojs/index.php/Young-Scholars-InWriting/index

Redd, B. R., \& Kennett, L. N. (2017). Getting students to read instructor feedback (and maybe actually learn from it). College Quarterly, 20(2). Retrieved from http:// collegequarterly.cal 